\title{
Methods that Assist Traction during Endoscopic Submucosal Dissection of Superficial Gastrointestinal Cancers: A Systematic Literature Review
}

\author{
Georgios Tziatzios, Alanna Ebigbo, Stefan Karl Gölder, Andreas Probst and Helmut Messmann \\ Department of Gastroenterology, University Hospital Augsburg, Augsburg, Germany
}

Endoscopic submucosal dissection (ESD) is a well-established method for the treatment of early-stage gastrointestinal neoplasms. Adequate submucosal exposure is one of the most significant factors related to an effective and safe dissection. The aim of this systematic review was to evaluate the efficacy and safety of various methods that assist traction during ESD of precancerous and earlystage neoplastic lesions of the gastrointestinal tract. We performed an electronic search of the MEDLINE and the Cochrane Controlled Trials Register databases for relevant studies published up to May 2019. Trials exclusively recruiting patients undergoing ESD for superficial gastrointestinal cancer were considered eligible for inclusion. Thirty-three articles including 3,134 patients met the inclusion criteria. The studies evaluated different approaches for widening the endoscopic view, including magnetic anchor-guided ESD (3 studies), use of a second endoscope (5 studies), clip-involving technique (21 studies), and miscellaneous methods (4 studies). Among them, only 6 were randomized controlled trials evaluating different approaches. Overall, the implementation of methods that assist traction during ESD significantly improved the operating time and R0 resection rate and decreased the rate of complications (bleeding and perforation). Interventions that assist traction seem efficacious in improving tissue traction, thus facilitating ESD performance. Clin Endosc 2020;53:286-301

Key Words: Dissection; Endoscopic; Method; Submucosal; Traction

\section{INTRODUCTION}

Endoscopic submucosal dissection (ESD) is a pioneer endoscopic method initially devised for the treatment of early-stage gastric neoplastic lesions. ${ }^{1}$ To date, ESD has been established as an efficient method that achieves en bloc and R0 resection regardless of the lesion size, not only for early gastric cancerous lesions but also for lesions located in the colon or esophagus, overcoming the limitations of piecemeal endo-

Received: July 27, 2019 Revised: September 15, 2019

Accepted: September 24, 2019

Correspondence: Georgios Tziatzios

Department of Gastroenterology, University Hospital Augsburg, Stenglinstraße 2, Augsburg 86156, Germany

Tel: +49-821-40001, Fax: +49-821-400-4585, E-mail: g_tziatzios@yahoo.gr ORCID: https://orcid.org/0000-0002-2945-6007

(c) This is an Open Access article distributed under the terms of the Creative Commons Attribution Non-Commercial License (http://creativecommons.org/ licenses/by-nc/3.0) which permits unrestricted non-commercial use, distribution, and reproduction in any medium, provided the original work is properly cited. scopic mucosal resection (EMR). ${ }^{2,3}$ Nonetheless, ESD remains a technically demanding and time-consuming procedure with a slow learning curve, particularly in Western countries. ${ }^{4,5}$ In addition, it is associated with higher rates of complications than EMR, including bleeding and perforation. ${ }^{6}$ The fundamental difficulty of the method lies in the accessibility of the submucosal layer during dissection. Meticulous identification of the dissection plane enables thorough recognition of the submucosal vessels and cutting line, thus reducing the risk of complications while increasing the possibility of achieving complete resection. ${ }^{7-11}$ Traction is a method that could deliver satisfactory tissue tension within the submucosa and facilitate visualization of the dissection plane. Although traction has been the focus of many studies, most of the previous studies have included a single patient, or at most a very small number of patients, or involved non-human subjects, limiting the generalizability of their results to daily clinical practice. As these studies are beyond the scope of this systematic review, 
we refer the readers to previous iterations. ${ }^{12-14}$ In this study, we addressed in a systematic manner all clinical studies involving only human participants, with the aim of providing further understanding of the traction methods that might substantially improve the safety and efficacy of ESD.

\section{MATERIALS AND METHODS}

\section{Protocol}

We conducted this review according to the Preferred Reporting Items for Systematic Reviews and Meta-analyses (PRISMA) recommendations (available in Supplementary 1). ${ }^{15}$ The protocol of the review can be accessed at the International Prospective Register of Systematic Reviews (PROSPERO registration number CRD42019135942).

\section{Criteria for eligibility}

The eligibility criteria were determined based on the PICO statement (P: patients undergoing ESD for gastrointestinal tract [GIT] precancerous/cancerous lesions; I: use of a method that enables traction to allow better exposure of the submucosal plane; C: comparison to conventional ESD; O: ESD outcomes including overall procedure time, curative resection [R0], resection speed, complication rate [bleeding or perforation], and recurrence rate as defined in each study). All types of trials published in the English language were considered eligible, whereas non-human studies, ex vivo or pilot studies, editorials, narrative reviews, case reports/series, video cases, and abstracts from conferences were excluded.

\section{Identification and selection of studies}

A computerized search of the MEDLINE and Cochrane Database of Systematic Reviews electronic databases for all relevant publications listed from database inception to May 2019 was performed. We combined the following search terms: "endoscopic submucosal dissection" and "traction" searched both as Medical Subject Headings and free-text terms. Moreover, the reference lists of the included original studies and pertinent reviews were manually searched for studies not initially identified. Our search strategy is detailed in Supplementary 2. Two members of the study team independently screened all initial abstracts. Subsequently, the full text of all eligible studies was independently assessed for eligibility. In case the full-text form of a study that appeared relevant could not be found, the corresponding author was contacted. If the author failed to provide missing information, the abstract was excluded. Any disagreements were resolved by consensus.

\section{Extraction of data items}

A structured form based on a Microsoft Excel sheet (Microsoft Co., Redmond, WA, USA) was used for data extraction. The following data were extracted from each study: first author name, study setting (publication year, origin), study design and primary outcome, type of intervention and comparator (if any), traction method, anatomical location of the ESD (esophagus, stomach, or colorectal area), level of endoscopist expertise (expert vs. non-expert), mean lesion size (as described in each study), presence of fibrosis, potential interference of the method during ESD (if provided by the study), endoscopist's subjective evaluation of the performance of each method, and outcomes (overall procedure time, curative resection [R0], resection speed, complication rate [bleeding or perforation], and recurrence rate as defined in each study).

\section{Methodological quality of studies}

The methodological quality of each study and the risk of bias of randomized and non-randomized studies were rated using the Cochrane Collaboration tool ${ }^{16}$ and Newcastle-Ottawa Scale, ${ }^{17}$ respectively. We used Review Manager 5.3 (The Nordic Cochrane Centre, The Cochrane Collaboration, Copenhagen, Denmark) software package to construct comparison plots.

\section{RESULTS}

\section{Selection of studies}

Our initial search generated 177 citations. After deduplication, 154 articles were retrieved and reviewed. Three more studies were identified after manual reference searching of the full-text articles. The inclusion criteria were met by 33 studies. ${ }^{18-50}$ Fig. 1. illustrates the search flow.

\section{Study characteristics}

Table 1 summarizes the main characteristics of the included studies. The publication date of the studies ranged from 2006 to 2019, cumulatively enrolling 3,134 participants. All but 2 studies ${ }^{38,46}$ were conducted in a single-site setting. Twenty-three had a prospective design ${ }^{18-23,26,27,29,30,32,33,35,37-41,44-47,50}$ and 10 had a retrospective design. . $2,25,28,31,34,36,42,43,48,49^{\text {Among }}$ the prospective studies, 6 were randomized controlled trials (RCTs). ${ }^{27,30,32,39,45,46}$ The majority of the studies $(n=31)$ were conducted in Eastern countries, whereas only 2 studies were conducted in Europe. ${ }^{38,48}$ With respect to the traction method, 3 studies evaluated magnetic anchor-guided ESD (MA-ESD), ${ }^{19,44,49} 5$ evaluated the efficacy of double endoscopes, ${ }^{22,27,28,40,48} 21$ investigated clip-involving methods for applying traction,,$^{24-26,29-39,41-43,45-47,50}$ and 4 assessed 
miscellaneous methods. ${ }^{18,20,21,23}$ Concerning the anatomical location where ESD was performed, 6 studies evaluated ESD traction methods for esophageal lesions, ${ }^{21,26,32,38,41,43} 17$ for stomach lesions, ${ }^{18-20,23,25,27-29,33,34,37,40,42,44,46-48}$ and 9 for colorectal lesions, ${ }^{22,24,30,35,36,39,45,49,50}$ whereas a single study ${ }^{31}$ enrolled patients with lesions in the stomach or colon. Data comparing the efficacy and safety of the traction methods between expert and non-expert endoscopists were available from only 5 studies, ${ }^{34,37,42,45,46}$ whereas ESD was performed by experts in all other studies. The mean lesion size, level of endoscopist expertise (expert vs. non-expert), endoscopist's subjective evaluation of the performance of the method, potential interference of the method with the ESD procedure, and the impact of each method on the main outcomes of the procedure are summarized in Table 2.

\section{Study quality and risk of bias}

The results of the risk of bias evaluation for the 6 RCTs $^{27,30,32,39,45,46}$ are shown in Fig. 2. The overall quality can be characterized as questionable (detection bias and performance bias were the principal drawbacks). The results of the quality assessment of observational studies according to the Newcastle-Ottawa scale are provided in Supplementary 3.

\section{Magnetic anchor-guided endoscopic submucosal dissection} MA-ESD is a sophisticated method allowing dynamic tissue retraction with a rotatable external magnet (permanent magnet and electromagnet are the 2 available types). Traction is independent of the movement of the endoscope, thus serving as a "second hand" for the endoscopist. ${ }^{10}$ Compared with other methods that produce traction, the main advantage of this method is the lack of interference with endoscopic maneuvers during ESD while the constant movement of the external magnet changes the direction of the retraction, thus resulting in a dynamic traction phenomenon. Gotoda et al. ${ }^{19}$ investigated the feasibility of MA-ESD with an extracorporeal magnet in a study enrolling 25 subjects with early gastric cancer. All lesions were successfully removed en bloc without complications. No recurrence was observed in any of the patients after a median follow-up of 20 months. These results indicated, for the first time, that the technique is feasible and safe while offering excellent visualization for gastric ESD. To overcome

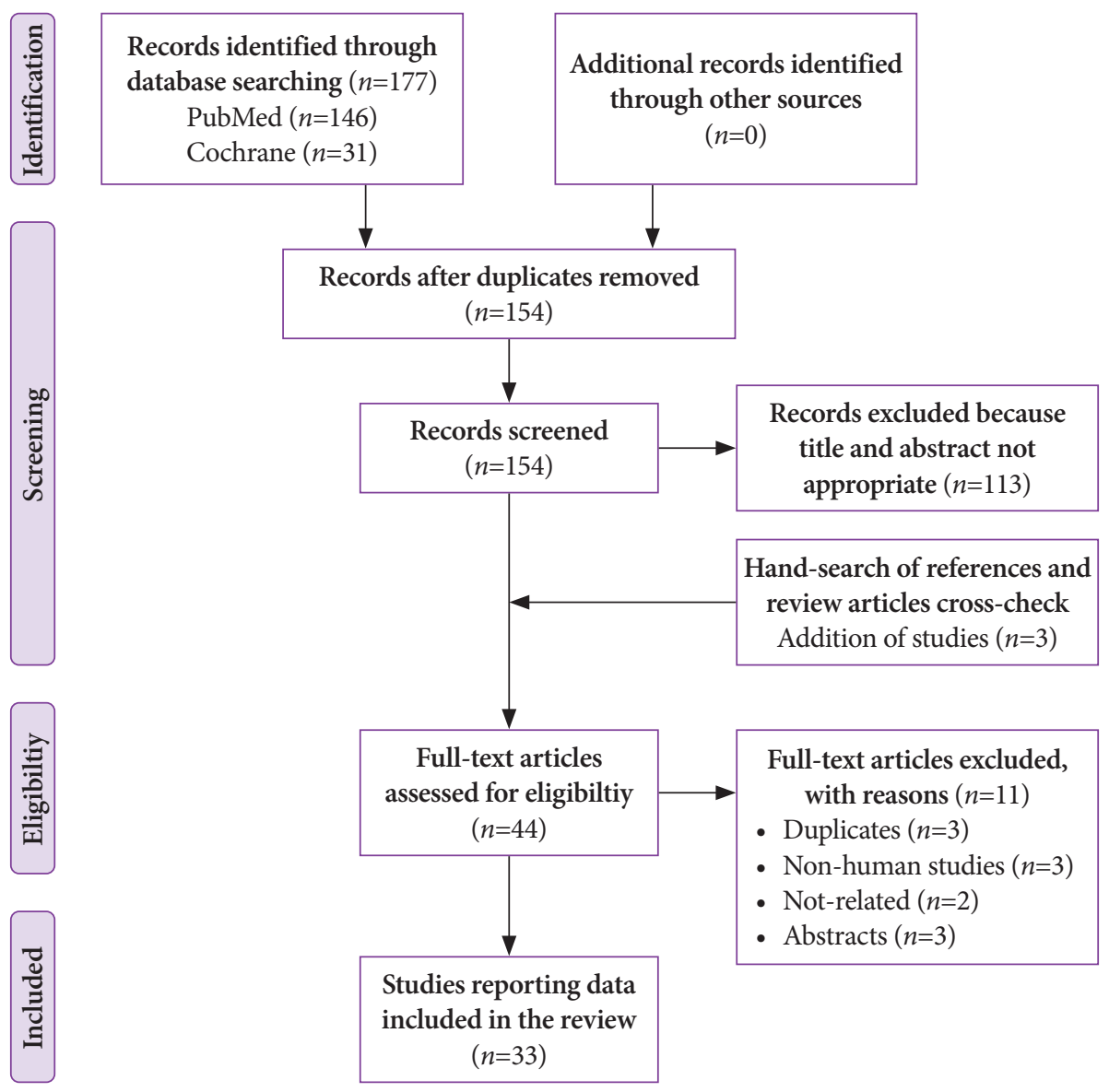

Fig. 1. Literature search flowchart and study selection. 


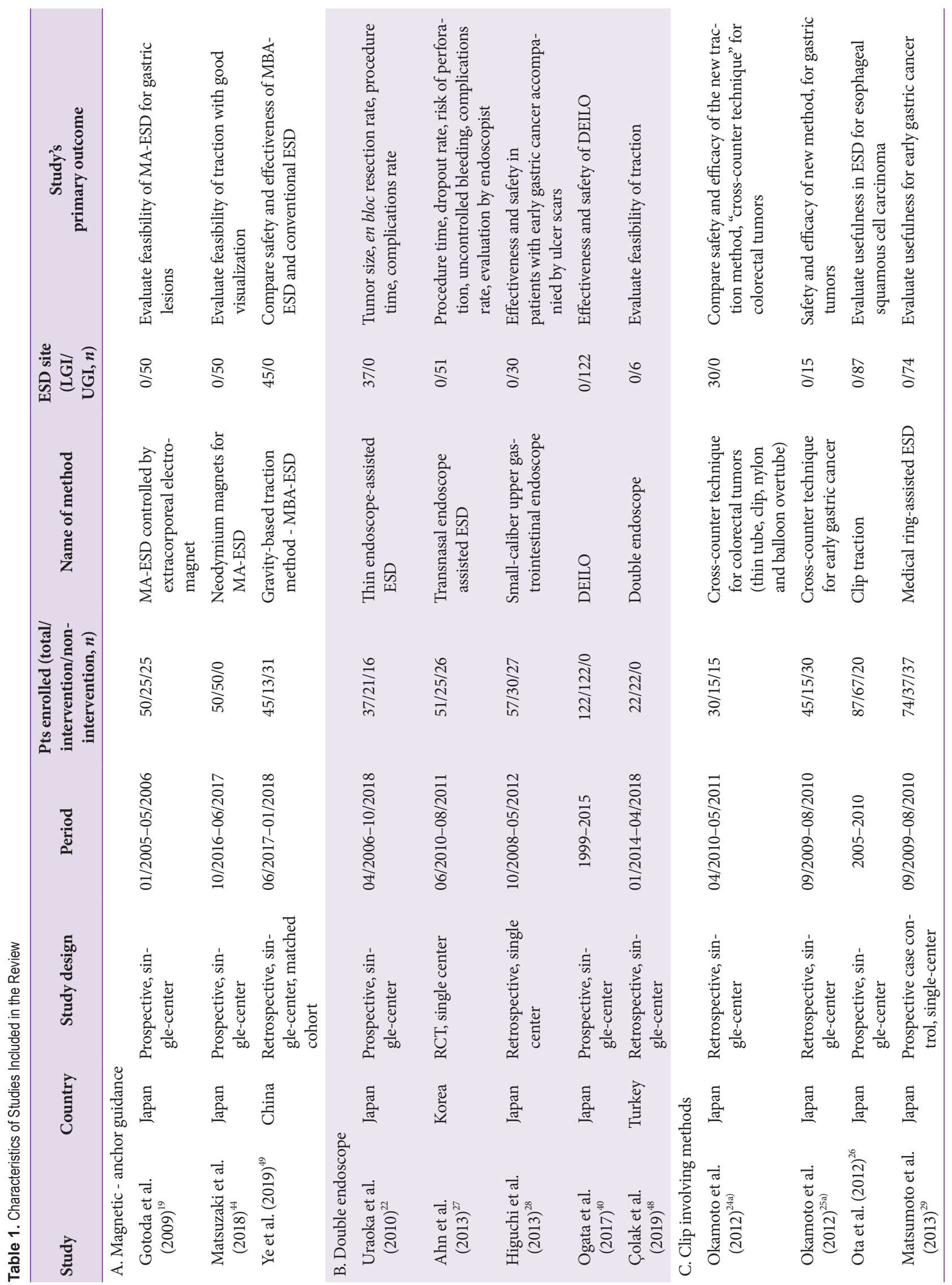




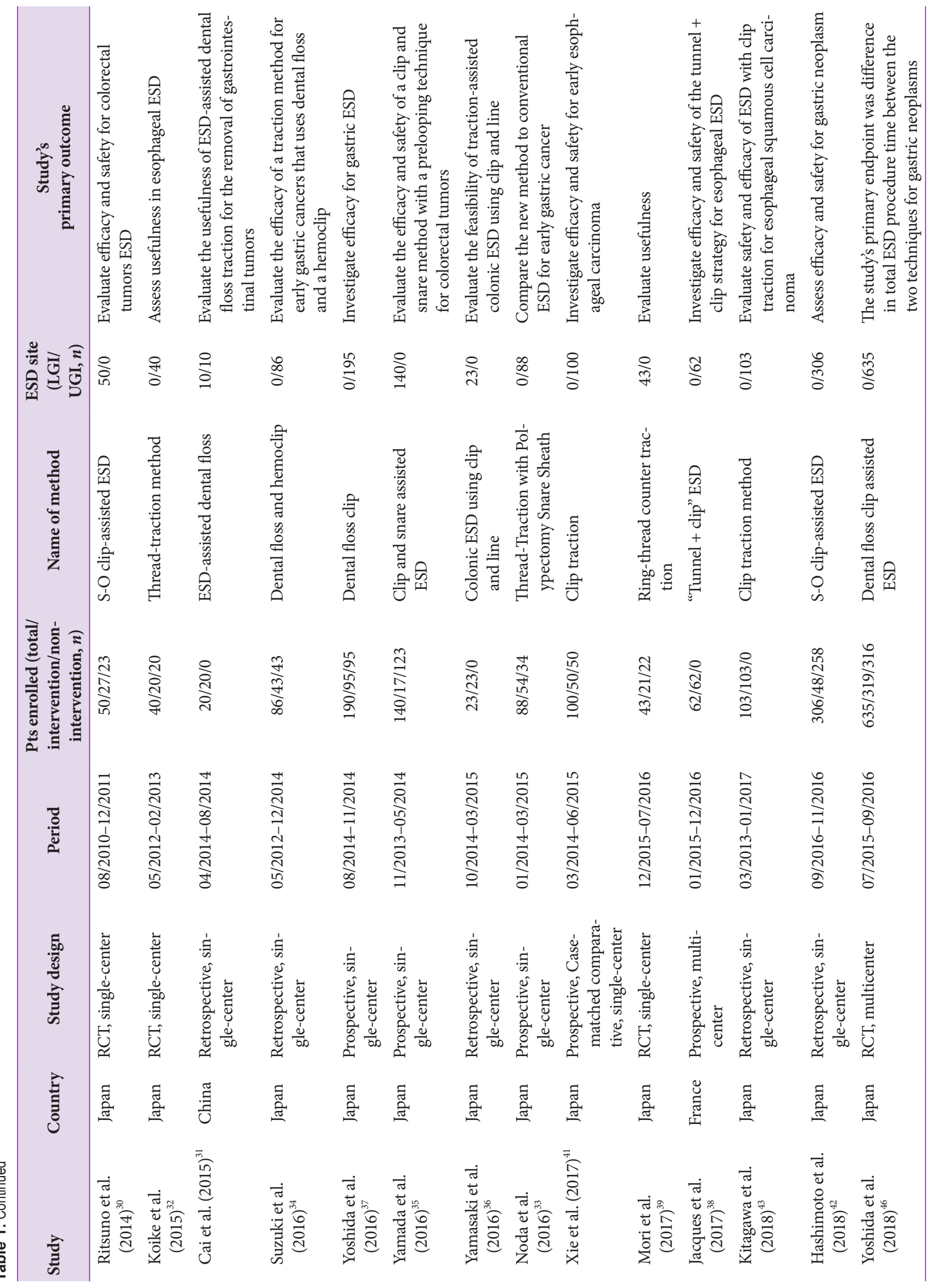




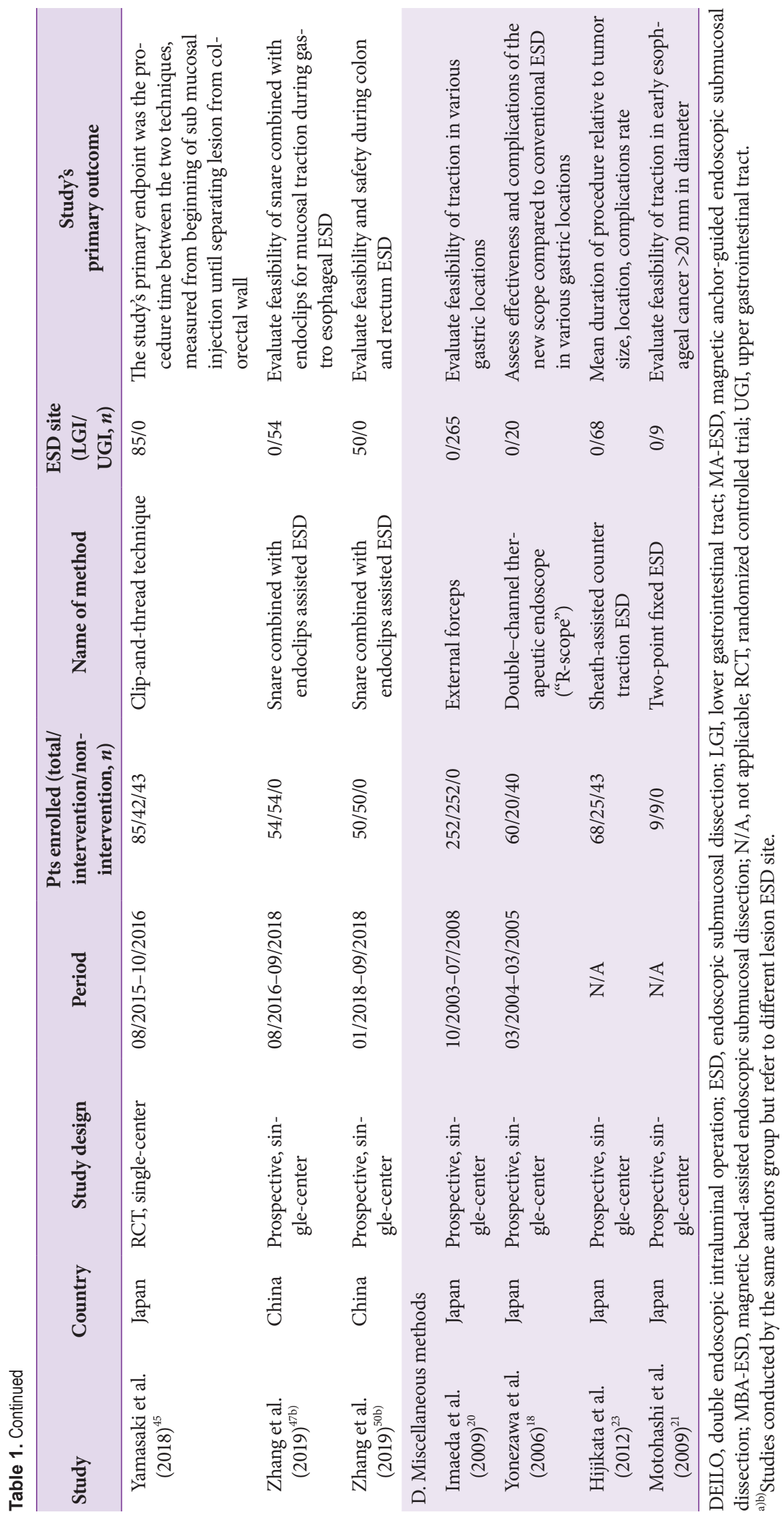


C cunnche enoscopy

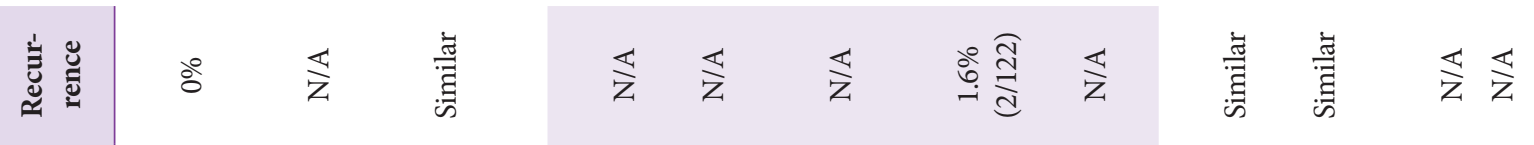

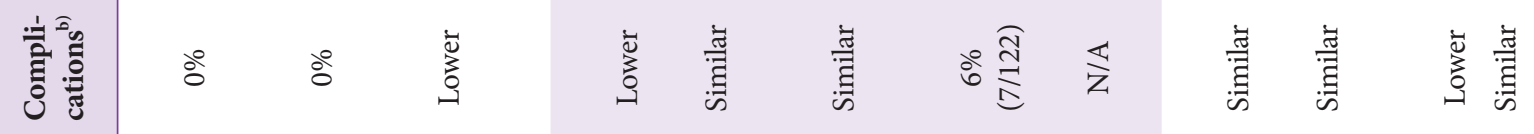

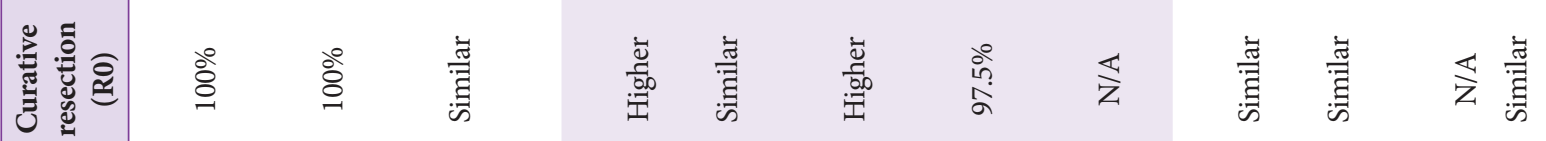

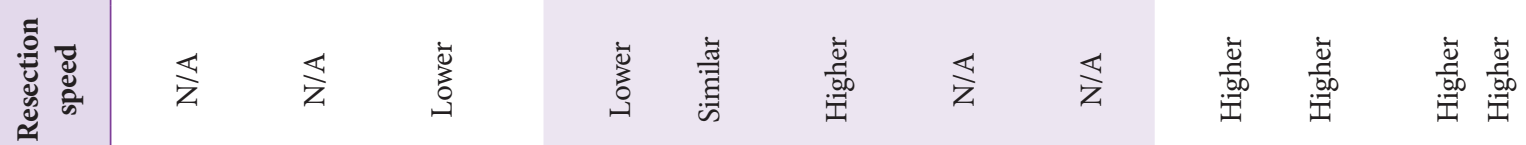

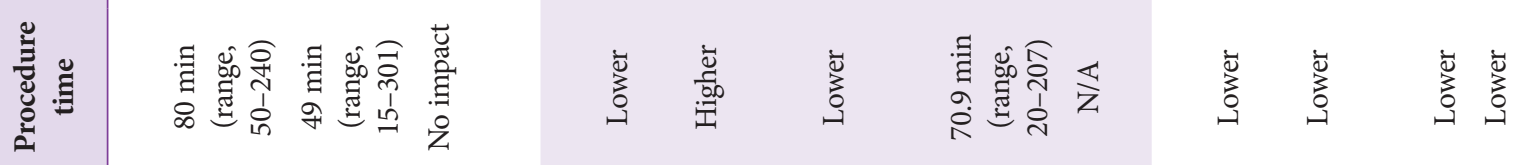

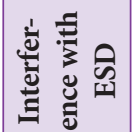

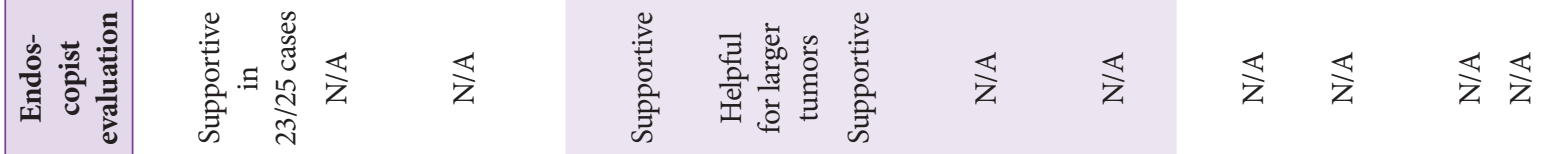

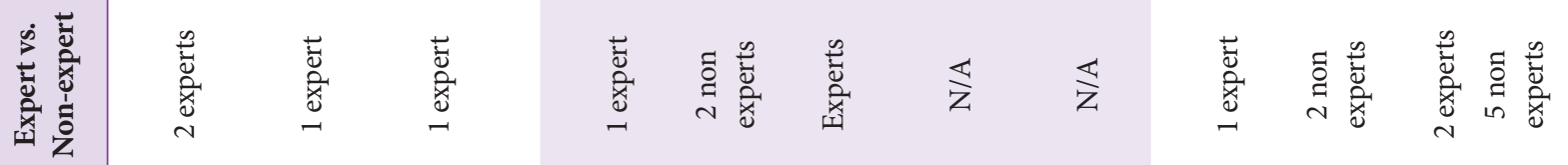

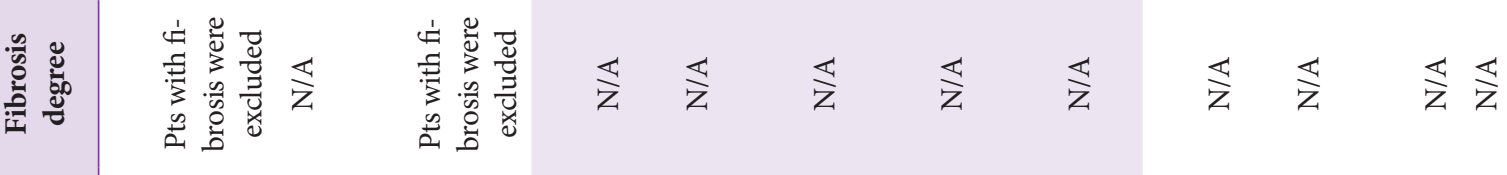

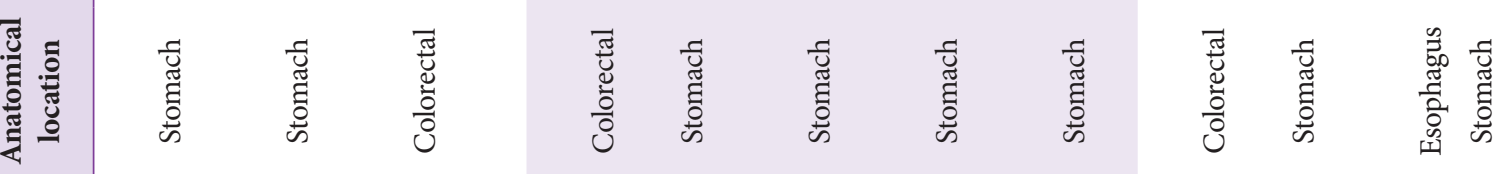

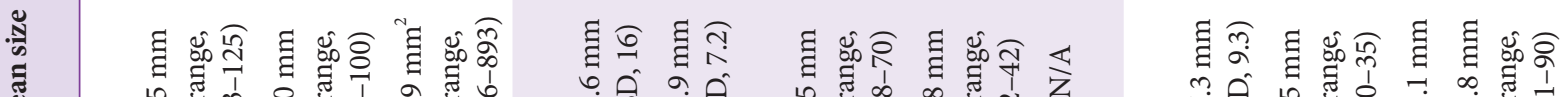

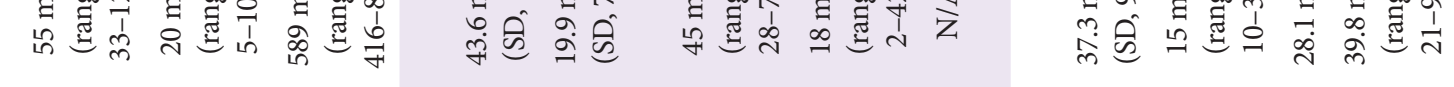

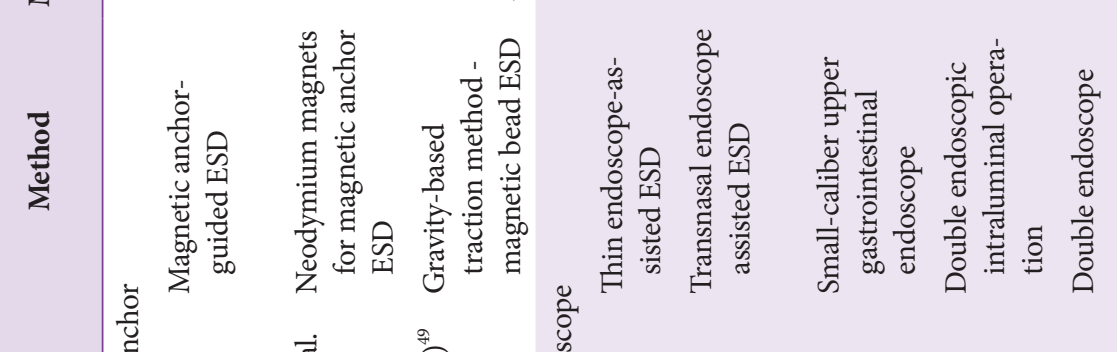

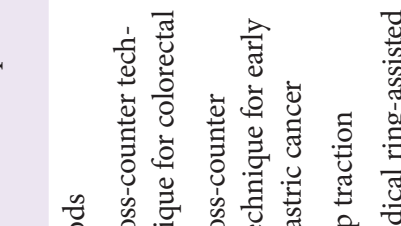

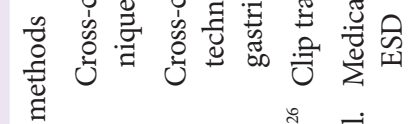

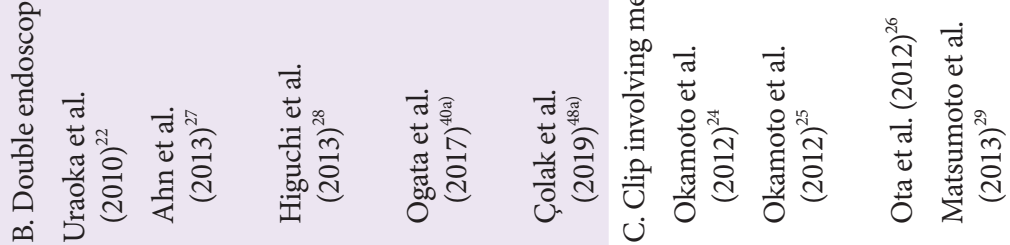




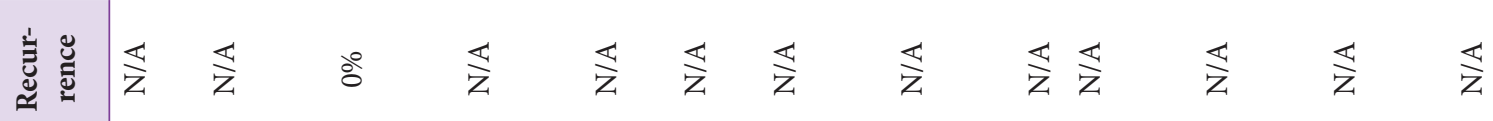

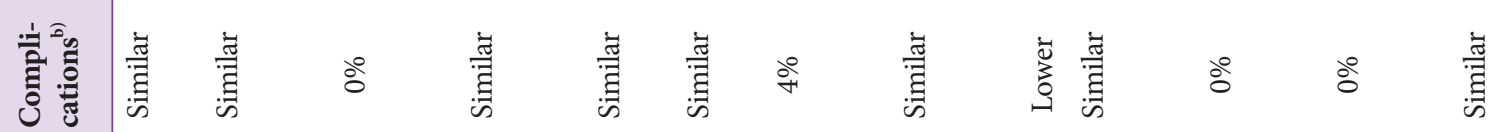

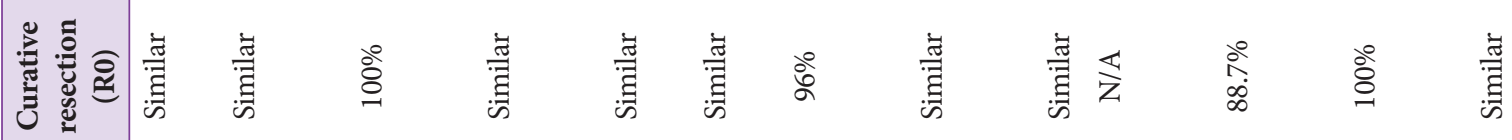

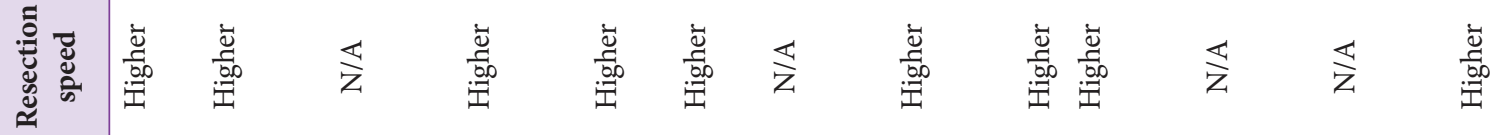

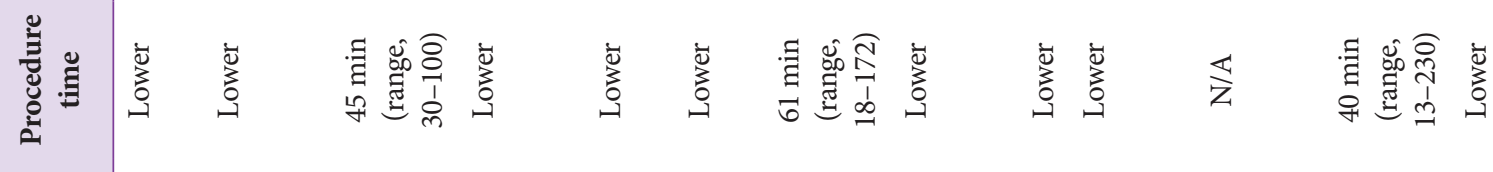

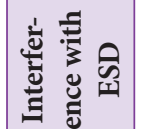

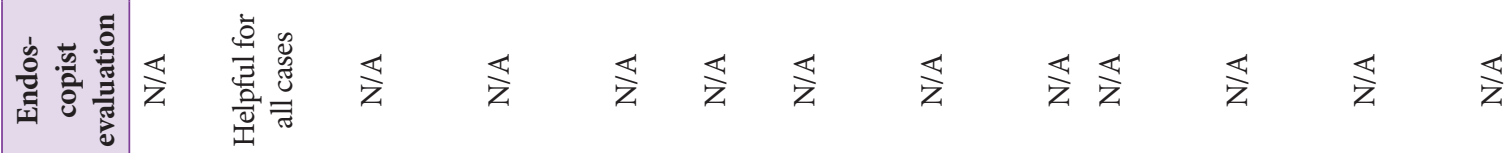

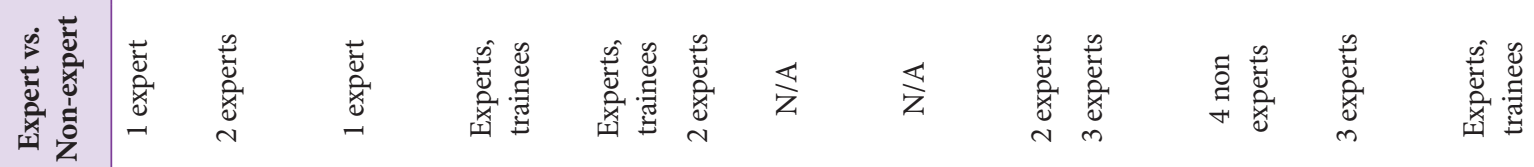

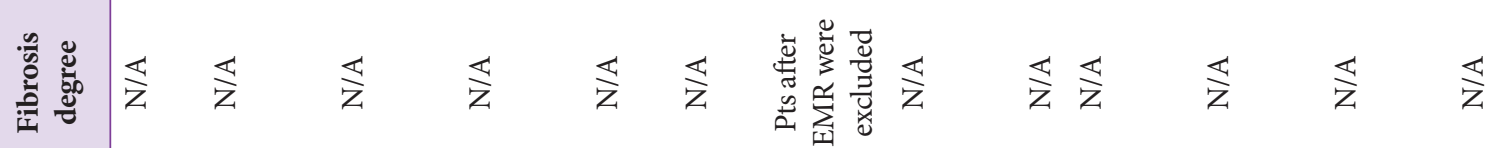

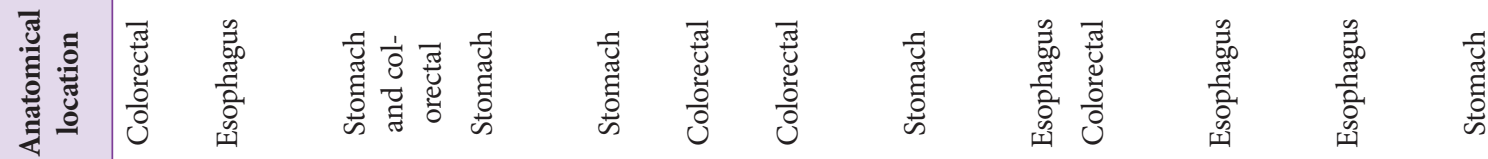

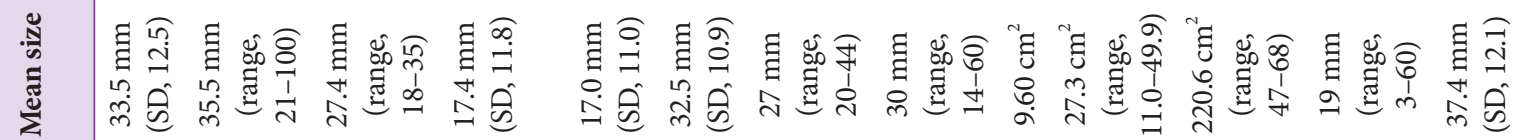

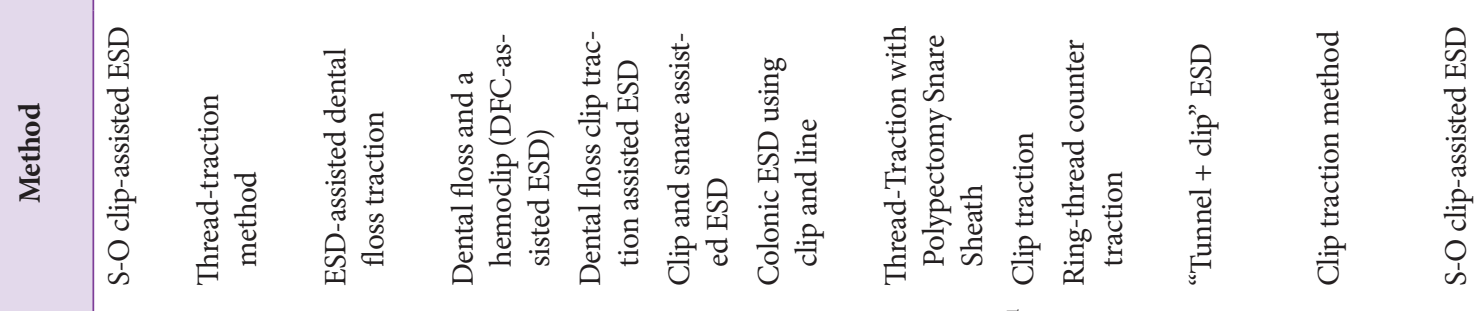

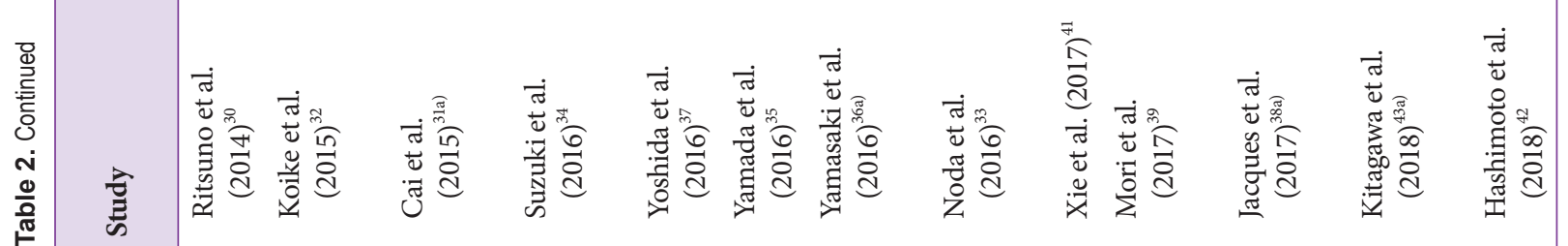


C clinical endoscopy

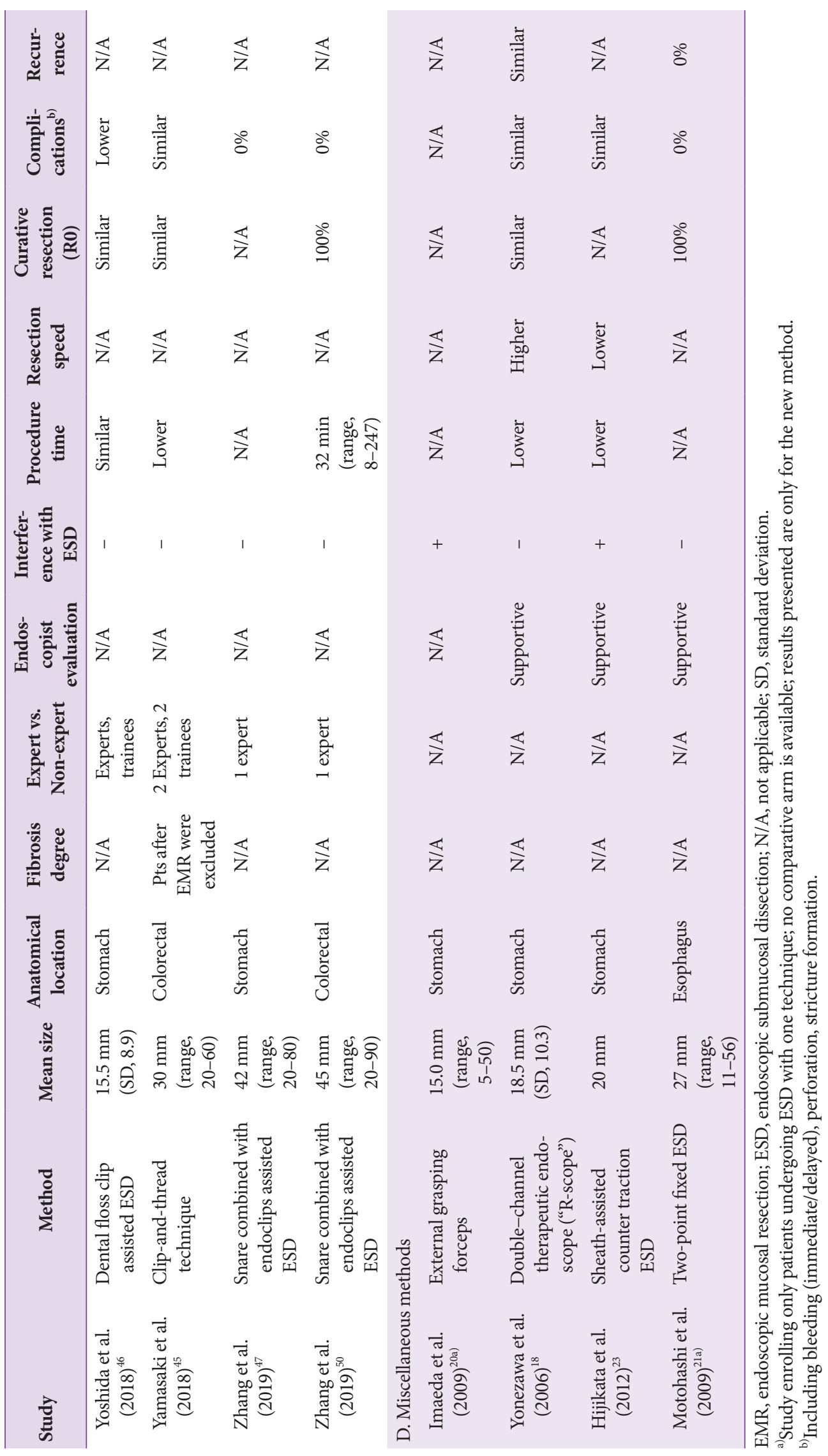


the main drawback of the method (i.e., the large size of the external electromagnet), Matsuzaki et al. ${ }^{44}$ conducted a feasibility study of MA-ESD with neodymium magnets for the treatment of gastric lesions. In the aforementioned trial, the magnetic traction consisted of an internal magnet attached to a clip. Although there were minor concerns about patient safety because of the low resistance to rust of the magnet after direct contact with human tissue, the authors reported obtaining adequate counter-traction in all cases, resulting in successful en bloc resection of lesions without adverse events or allergic reactions. Recently, Ye et al. ${ }^{49}$ in their retrospective study compared the efficacy and safety of magnetic bead-assisted ESD (MBA-ESD) with those of standard ESD for large colorectal cancerous lesions. Despite the low enrollment in the study $(n=26)$, the results supported the notion that MBAESD is equivalent to conventional ESD in terms of en bloc and R0 colonic resection as well as local recurrence. Furthermore, complications were totally absent ( $0 \%$ in the MBA-ESD group vs. $38.5 \%$ in the standard ESD group, $p=0.039$ ) while other

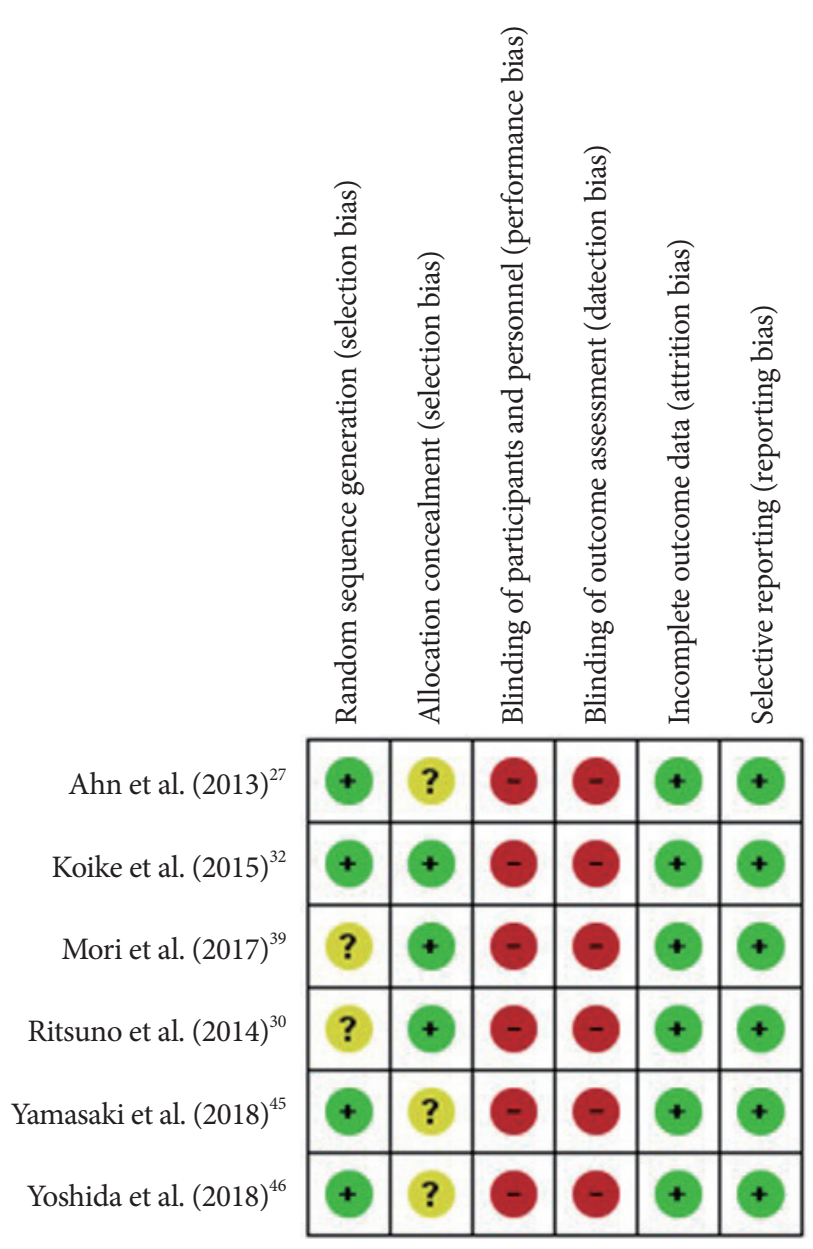

Fig. 2. Risk of bias among randomized controlled trials included in this review. procedure-related parameters (i.e., dissection time and speed) also improved.

\section{Use of double endoscopes}

The implementation of a second endoscope to facilitate traction has been particularly considered for treating lesions that are difficult to resect with conventional ESD. As a rule, the initial circumferential incision is performed using the primary endoscope, followed by the insertion of a thinner endoscope that applies traction to the lesion through common grasping forceps passed through its working channel. ${ }^{14}$ The method is "operator friendly", as it enhances the accessibility of the submucosa and increases the efficiency of submucosal dissection while reducing the risk of complications. Uraoka et al. $^{22}$ reached the conclusion that the double-endoscope approach is technically easier and safer for large colorectal tumors. However, the method was applied only to rectal and rectosigmoid lesions, creating doubts about the efficacy of the method in more proximal colonic lesions. Moreover, the need for an additional person to operate the traction system and for a second light source represents further weaknesses. In an attempt to provide further clarifications, Higuchi et al. ${ }^{28}$ conducted a retrospective study introducing an improved version of the method for early gastric cancer, in which a unique, switchable light source between the endoscopes was used. Although comparisons were made with historical control data, the cutting rate into specimens was improved ( $7 \%$ vs. $35 \%, p=0.01$ ) with the double-endoscope method, with no serious adverse events noted. These results, however, were later refuted by the only RCT available on this matter. ${ }^{27}$ Ahn et al. ${ }^{27}$ found that the main outcomes of ESD were similar between endoscope-assisted ESD and standard ESD when used for gastric neoplastic lesions. Although the study was well designed, the enrollment of a low number of patients $(n=51)$ and the performance of ESD procedures by inexperienced endoscopists are the main points of critique. Thereafter, results from 1 Western center and 1 Eastern were reported. The Western results, from a retrospective follow-up study originating from Turkey, showed no difference in the procedure duration and complication rate when using the double-endoscope method for upper gastrointestinal lesions. ${ }^{48}$ Ogata et al., ${ }^{40}$ by enrolling relatively more subjects $(n=122)$ with a long mean follow-up period (24 months), highlighted the safety and efficacy of a double-endoscopic intraluminal operation for precancerous gastric lesions. Taken together, these studies demonstrated somewhat conflicting results about the role of the double-endoscope method in ESD; however, they should be critically taken into account considering the low number of patients and the variable follow-up period. 


\section{Clip-involving methods}

Accumulating evidence has highlighted the impact of clip traction on the technical outcomes of ESD, as well as its therapeutic and prognostic implications. Early studies showed that traction produced by clips can significantly reduce the overall procedure time compared with standard ESD, with the results being consistent for both gastric and colonic precancerous lesions. ${ }^{24-26}$ This finding was also supported by other studies evaluating the efficacy of ESD with dental floss clip traction in several locations inside the GIT..$^{31,34,36,37,41,43}$ On the other hand, data from RCTs attempting to investigate any potential benefit in terms of procedural outcomes when using clip-related methods seem somewhat conflicting. The earliest study ${ }^{32}$ showed that the thread-traction method resulted in significant shortening of the dissection time compared with conventional ESD in esophageal lesions (19.8 min vs. $31.8 \mathrm{~min}, p=0.044$ ). Accordingly, Mori et al. ${ }^{39}$ reported that ring-thread counter traction also optimized the total dissection time in colorectal ESD (130.0 [56.0-240.0] min vs. 80 [35.0-130.0] $\mathrm{min}, p=0.001)$. In another very recent Japanese RCT enrolling 84 patients with $\geq 20 \mathrm{~mm}$ superficial colorectal neoplasms, the clip-andthread technique was related not only to a shorter procedure time (40 [11-86] $\mathrm{min}$ vs. 70 [30-180] $\mathrm{min}, p<0.0001)$ but also to a higher self-completion rate in non-experts $(100 \%$ [39/39] vs. $90 \%$ [36/40], $p=0.04$ ) than conventional ESD. ${ }^{45}$ However, the results published in the largest RCT thus far seem to refute the role of traction-assisted ESD for gastric neoplasms reported in the aforementioned studies. In that study, ${ }^{46} 640$ participants with gastric neoplasms were randomized at 14 centers across Japan to undergo standard ESD or ESD in which a dental floss clip was used to provide traction, with the ESD procedure time being the primary endpoint. No difference was observed in the mean ESD procedure time between the 2 methods (60.7 min vs. $58.1 \mathrm{~min}, p=0.45$ ). However, perforation was less frequent in patients treated with dental floss clip traction-assisted ESD ( $2.2 \%$ vs. $0.3 \%, p=0.04)$. On the other hand, the new technique was particularly beneficial for lesions located in the greater curvature of the stomach, for which the mean procedure time was effectively reduced (104.1 $\min$ vs. $57.2 \mathrm{~min}, p=0.01$ ). The clip-and-snare method has been reported to be another promising technique because it requires no special equipment to enable pushing and pulling movements without impairing flexibility. The technique was found to have a significant impact on the procedure time (45.6 min vs. $70.1 \mathrm{~min}$ [vs. control group], $p=0.047$ ), with a lower complication rate $(5.9 \%$ vs. $8.1 \%, p=1.00) .{ }^{35}$ Noda et al. ${ }^{33}$ used a sheath of a polypectomy snare to create traction and achieved faster resection time, which was uniform among endoscopists of various skill levels. In keeping with the findings of those reports, the approach of inserting a selective snare along with the endoscope has also been shown to be safe and feasible in ESD of colonic and gastric intraepithelial neoplasia. ${ }^{47,50}$ An alternative internal traction method using the S-O clip for treating colorectal lesions has been recommended. The device is advanced through the working channel of an endoscope and functions independently of endoscope movements. The safety and efficacy of the method were first evaluated in a prospective RCT, which showed that the mean ESD time for large colorectal tumors ( $>20 \mathrm{~mm}$ diameter) was significantly reduced when the S-O clip was used, compared with the standard technique $(37.4 \pm 32.6 \mathrm{~min}$ vs. $67.1 \pm 44.1 \mathrm{~min}, p=0.03) .{ }^{30}$ Similar results were also obtained in terms of the efficacy of the clip in the treatment of upper GIT epithelial neoplasms in a recent large retrospective Japanese study. The mean procedure time was significantly shorter in the S-O clip group (47.2 $\pm 24.6 \mathrm{~min}$ vs. $69.2 \pm 67.1 \mathrm{~min}, p=0.035)$, with similar results in secondary outcomes to those of standard ESD (en bloc resection rate: $100 \%$ vs. $100 \%, p=1.000$; perforation rate: $0 \%$ vs. $2.1 \%, p=0.315$; and delayed bleeding rate: $2.1 \%$ vs. $4.3 \%, p=0.558) .{ }^{42}$ In another Japanese study, Matsumoto et al. ${ }^{29}$ reported on the use of a "medical ring" during ESD in a prospective case-control study. The newly developed ring allowed adequate visualization, thus enhancing the performance of gastric ESD relative to the conventional procedure $\left(3.18 \pm 2.29\right.$ dissection $\mathrm{min} / \mathrm{cm}^{2}$ vs. $6.3 \pm 3.6$ dissection $\left.\mathrm{min} / \mathrm{cm}^{2}, p<0.01\right)$. Taking these observations into account, it is evident that more robust data are definitely needed in order to assess the performance of these novel methods overall and in specific populations.

\section{Miscellaneous methods}

We identified 4 studies ${ }^{18,20,21,23}$ evaluating various methods to improve traction during an ESD procedure. More than a decade ago, Yonezawa et al., ${ }^{18}$ in a well-designed, 12-month follow-up prospective trial of 60 patients, showed that the use of a sophisticated double-channel endoscope ("R-scope") resulted in significantly shorter operating time than standard ESD (57.9 \pm 29.7 min vs. $92.8 \pm 58.9$ min, $p=0.016$ ), with similar efficacy and complication rates. Three years later, Motohashi et al. ${ }^{21}$ presented a novel method-the 2-point fixed ESD-for esophageal cancerous lesions that allowed traction to the site of dissection by using a hood fitted with a forceps channel. Their results implied that the technique is feasible for esophageal lesions. In an effort to optimize ESD procedures, authors from a large prospective Eastern trial used external biopsy forceps for early-stage gastric cancer. ${ }^{20}$ Despite the promising results in terms of low mean procedure time, the method also had an important inherent shortcoming (i.e., inability to be performed when the lesion is located in other gastric sections such as the cardia and lesser curvature). Further insights into the clinical outcomes of traction-assisted ESD 
were provided by a small, single-center study that investigated the utility of the novel sheath for ESD. ${ }^{23} \mathrm{~A}$ total of 43 and 25 consecutive patients with early gastric carcinomas treated using the standard method and the new method, respectively, were compared. The use of the novel sheath was not only less time-consuming for lesions sized $20 \mathrm{~mm}$ and for all resected tumors regardless of location but was also technically simpler. Undoubtedly, the confirmation or rejection of these results requires more evidence because relevant prospective data are lacking.

\section{Efficacy and safety of traction methods based on the anatomical site of endoscopic submucosal dissection}

Although data comparing the efficacy and safety of various traction methods according to the anatomical location of ESD are lacking, clip-involving techniques and their modifications seem to be efficacious in providing sufficient traction in all GIT sites, offering particular benefits for lesions located in the esophagus and greater curvature of the gastric body. The use of a second endoscope has shown considerable efficacy in treating lesions located in the distal colon (sigmoid and rectum), whereas its usefulness for more proximal tumors is questionable. The method also seems advantageous for patients with gastric neoplasms. For magnet-assisted ESD, most of the data were derived from patients with upper GIT lesions, whereas its efficacy in colorectal tumor treatment remains to be established. Finally, as studies evaluating miscellaneous methods exclusively enrolled patients with tumors in the upper GIT (esophagus and stomach), it can be assumed that the efficacy of the methods is limited to those locations.

\section{Efficacy of traction methods based on the expertise level of the endoscopist}

Five studies ${ }^{34,37,42,45,46}$-all evaluating clip-involving methods-provided data about the impact of the endoscopist's expertise level (expert vs. non expert) on ESD outcomes. Overall, the data showed that in terms of procedure time, the traction methods were mostly beneficial for expert endoscopists. Although the procedure time also improved when non-experts used traction methods, the difference did not reach significance in most studies. Notably, these findings were not verified by the largest $\mathrm{RCT}^{46}$ which reported no difference in procedural time regardless of the operator's experience.

\section{Endoscopist's evaluation of the traction method and interference with the endoscopic submucosal dissection procedure}

Eight studies ${ }^{18,19,21-23,27,28,32}$ reported on the endoscopist's subjective evaluation of the traction method performance. Over- all, the results suggested that traction methods are supportive and helpful during ESD. The results on the interference of each method with the ESD procedure are presented in Table 2. The MA-ESD and clip-involving methods cause potentially no or minimal interference; however, this does not apply when double endoscopes are used, as significant interference between the 2 devices can be noted.

\section{Overall comparison of methods}

The use of magnets represents an innovative method of delivering traction during ESD. Compared with the other methods, the principal advantage of MA-ESD is that the traction applied to the ESD site is independent (i.e., easily adaptable without any interference with endoscope movement). On the other hand, the applicability of the method is limited by the significant decrease in force as the distance between the magnets increases (i.e., in cases of a thick abdominal wall). The large size of the magnets, scant data for the efficacy of the method for colorectal lesions, additional financial burden, and potential effects on the human body are also issues that should not be underestimated. The double-endoscope method can be a rewarding, handy option that allows traction to be effectively adjusted in any direction merely through standard maneuvering of a second endoscope-a procedure familiar to all endoscopists. However, the major flaw of this method is that the 2 endoscopes may interfere with each other. Although the use of a single transferable light source between the 2 endoscopes has been reported, ${ }^{28}$ the method requires, in most cases, dual light sources, endoscopes, and physicians, making it an expensive approach. The method can be efficacious for upper GIT lesions, for which it has been mainly evaluated; however, in terms of colonic ESD, its competence is limited to distal colonic and rectal tumors. On the other hand, clip-involving methods and their modifications are, in most cases, relatively simple to use, can be applied to any site, do not require additional special equipment, and have a low cost; thus, they can be easily integrated into daily clinical practice. Notably, they can be particularly useful for some lesions such as those located in the greater curvature of the gastric body. However, they are not without caveats. Traction can be rather difficult to adjust as pulling is the only option. Moreover, the clip can be detached from tissue, necessitating repetition of the procedure, which is a troublesome task when the lesion lies in the proximal colon. The application of miscellaneous methods is limited owing to the paucity of data about their efficacy; thus, they cannot be recommended at a large scale. Taking these observations into account, it is evident that more robust data are definitely needed to assess the performance of these novel methods overall and in specific populations. 


\section{CONCLUSIONS}

A large variety of endoscopic methods and novel devices has been introduced with the aim of improving traction during ESD. Despite the promising results, data about the overall and comparative efficacy of the methods remain scarce, thus preventing their integration into daily clinical practice. For the first time, we addressed in a systematic manner the knowledge deficit about the role of all available endoscopic methods and devices used to assist traction in ESD.

Our review indicated that multiple disparate endoscopic methods have the potential to improve tissue tension and facilitate visualization during ESD. Indeed, the majority of the studies uniformly showed that the implementation of any method results in significant improvement in the core quality features (overall operating time and complication rate) of each procedure relative to standard ESD. However, the studies reviewed here did not allow drawing firm conclusions on how to best achieve traction during ESD, as there was no evidence supporting the superiority of any of the strategies. Instead, endoscopists may consider adopting a method on a case-by-case basis, taking into account several factors such as lesion characteristics, proficiency level of the endoscopist, and availability of the method in a given health-care setting.

Undoubtedly, these technological advances can be considered adjuvant approaches to improve physician performance during ESD. ${ }^{14}$ On the other hand, it can be argued that their true benefit remains questionable at a time when a simple and costless alternative-traction by gravity-may be equally effective (Fig. 3). Gravity can induce traction, thus abolishing the need for any additional device by allowing controlling the direction of the traction force merely through changing the patient's position according to intraluminal fluid location. ${ }^{14}$ However, a head-to-head comparative evaluation between traction by gravity and any other traction technique is still lacking. Nonetheless, even traction by gravity is far from being the perfect concept, as the submucosal view may be not be sufficient during the initial stages of the procedure, when the flap is not yet sufficiently exposed, or in non-expert hands.

An issue that remains to be elucidated is whether the efficacy and safety of the traction methods differ according to the anatomical location of the ESD procedure or the expertise level of the endoscopist. Although direct comparisons with respect to anatomical sites are totally absent, it seems that clip-involving methods have a beneficial effect on ESD outcomes throughout the GIT, particularly for the stomach. On the other hand, double-endoscope-assisted ESD is particularly efficacious in treating distal colonic (sigmoid, rectum) tumors. As far as the expertise level of the endoscopist is concerned, the majority of the studies showed that traction methods significantly improved ESD outcomes in expert hands. The latter seems to be also the case when the performance of non-experts comes into question. However, this finding was not consistent with the results of a large $\mathrm{RCT}^{46}$ that refuted the impact of the operator's experience on procedure time, thus underlining the need for more data to verify this hypothesis.

Although the many technical interventions presented in this review seem to be beneficial in terms of improving ESD outcomes, concerns about the quality of the studies are raised. It should be underlined that most of the studies originated from expert centers, which limits the external validity (i.e., generalizability) of the results. ${ }^{2,12}$ Additional studies are warranted to examine whether the results also apply to different hospital settings. Moreover, most of the studies had a single-center and retrospective design, enrolled populations with divergent ESD indications, or only aimed to prove the feasibility of a new method rather than to offer comparative results. Even results from published RCTs should be interpreted with caution because of serious study limitations. Surprisingly, the largest RCT meeting our eligibility criteria ${ }^{46}$ suggested that dental floss clip-assisted ESD traction does not reduce the procedure time.

Our review could also have significant implications on future research directions. Future studies should systematically assess endoscopist-related (e.g., variable level of skill), patient-related (e.g., location and type of the lesion), and
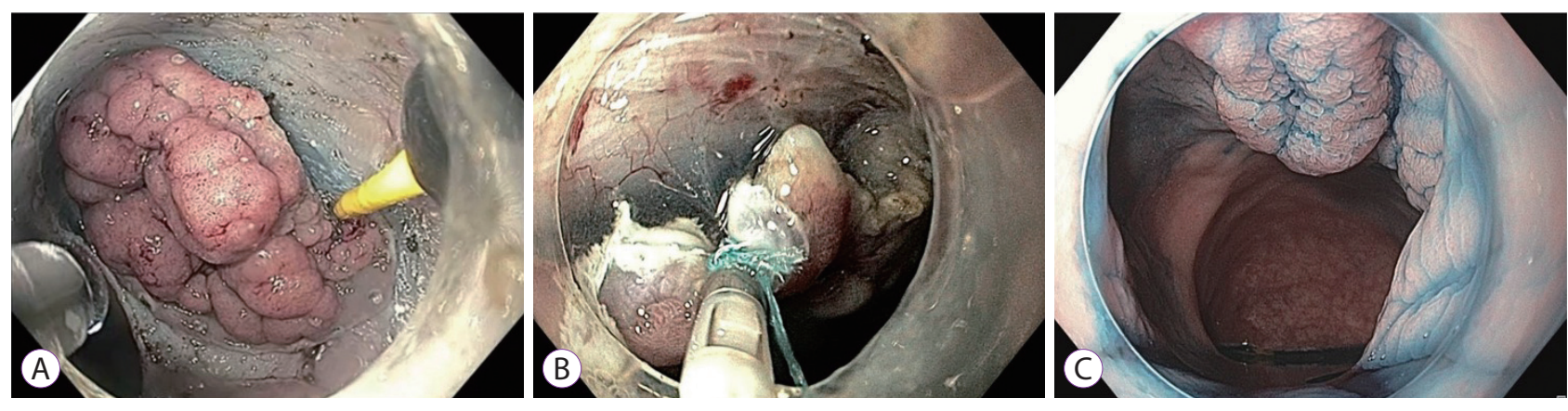

Fig. 3. Traction methods: (A) double-endoscope method, (B) clip-with-line method, and (C) traction by gravity. 
setting-related factors in an effort to reach solid conclusions about the real-world effectiveness of the techniques. Likewise, efforts should be made to perform comparative evaluations of different approaches, as a further step toward optimization of the ESD procedure. Finally, future studies will benefit from larger sample sizes, which will provide not only additional evidence for efficacy but also adequate statistical power to detect changes in consequential clinical and procedural outcomes.

Effective and safe endoscopic removal or GIT precancerous lesions always remains a focal point. New medical devices that provide and facilitate tissue retraction in special cases have already emerged. Among them, a new device consisting of a double-balloon platform and a sheath (DiLumen Endolumenal Interventional Platform; Lumendi Ltd., High Wycombe, UK) has recently been shown to facilitate exposure of difficult-to-access lesions owing to poor endoscope maneuverability and loop presence. ${ }^{8}$ Another endoscopic system (ORISE TRS; Boston Scientific Co., Marlborough, MA, USA) has been reported to facilitate challenging colorectal ESD because of significant fibrosis from previous tattooing, by providing constant traction and adequate view of the field to be dissected. ${ }^{9}$ Finally, an exterior supplementary working channel (Ovesco, Tübingen, Germany) device mounted on the tip of a standard endoscope was recently introduced, allowing an additional endoscopic tool to be used for traction. ${ }^{11}$ The adjustable distance between working channels makes the device suitable not only for ESD but also for EMR without the need for a dual-channel endoscope.

A number of strengths of this study could be cited. We used a rigorous methodology and performed a recursive bibliographic search including a detailed search of all pertinent bibliographies. The independent assessment of eligibility and strict evaluation of study quality are considered additional advantages. Our effort adds to the existing literature by addressing the topic of traction during ESD based on data exclusively from human studies, adding to the understanding of how existing studies, despite their inherent caveats, may still guide clinical practice with the eventual aim of highlighting potential fields for future research.

Our work also has a number of limitations that merit further discussion. First, we did not perform a meta-analysis; however, the presence of statistical and clinical heterogeneities among the studies (different designs, variable indications and endoscopist skill levels, distinct techniques evaluated) would have made a quantitative meta-analysis inappropriate. In this regard, the possibility of publication bias cannot be ruled out. Furthermore, the lack of additional database search (i.e., EMBASE), English-language restriction, and Eastern origin of the majority of the studies also represent weaknesses of this review. Finally, the studies tend to have limited validity given the setting where they were conducted.

In summary, evidence from this systematic review suggests that several methods, including MA-ESD, use of double endoscopes, clip-involving techniques, and others, seem to be effective in improving the performance of ESD in patients with variable gastrointestinal lesions. Each method presents distinct advantages but also has considerable drawbacks, as outlined in Tables 1 and 2. Although none of the methods have sufficient evidence to be recommended at a large scale, interventional endoscopists should be aware of them in the pursuit of strategies for improving ESD performance.

\section{Conflicts of Interest}

Georgios Tziatzios is a scholar of the Hellenic Society of Gastroenterology. The other authors have no financial conflicts of interest.

\author{
Author Contributions \\ Conceptualization: Helmut Messmann \\ Data curation: Georgios Tziatzios, Alanna Ebigbo, Stefan Karl Gölder, \\ Andreas Probst, HM \\ Formal analysis: GT, AE, SKG, AP, HM \\ Investigation: GT, AE, SKG, AP, HM \\ Methodology: GT, AE, SKG, AP, HM \\ Project administration: GT, AE, SKG, AP, HM \\ Resources: GT, AE, SKG, AP, HM \\ Software: GT, AE, SKG, AP, HM \\ Supervision: GT, AE, SKG, AP, HM \\ Validation: GT, AE, SKG, AP, HM \\ Visualization: GT, AE, SKG, AP, HM \\ Writing-review\&editing: GT, AE, SKG, AP, HM
}

\section{ORCID}

Alanna Ebigbo: https://orcid.org/0000-0001-7765-035X

Stefan Karl Gölder: https://orcid.org/0000-0003-4507-5770

Andreas Probst: https://orcid.org/0000-0002-1486-9298

Helmut Messmann: https://orcid.org/0000-0002-4026-6837

\section{REFERENCES}

1. Fuccio L, Ponchon T. Colorectal endoscopic submucosal dissection (ESD). Best Pract Res Clin Gastroenterol 2017;31:473-480.

2. Pimentel-Nunes P, Dinis-Ribeiro M, Ponchon T, et al. Endoscopic submucosal dissection: European Society of Gastrointestinal Endoscopy (ESGE) guideline. Endoscopy 2015;47:829-854.

3. Saito Y, Fukuzawa M, Matsuda T, et al. Clinical outcome of endoscopic submucosal dissection versus endoscopic mucosal resection of large colorectal tumors as determined by curative resection. Surg Endosc 2010;24:343-352.

4. Probst A, Golger D, Anthuber M, Märkl B, Messmann H. Endoscopic submucosal dissection in large sessile lesions of the rectosigmoid: learning curve in a European center. Endoscopy 2012;44:660-667.

5. Probst A, Ebigbo A, Märkl B, et al. Endoscopic submucosal dissection for early rectal neoplasia: experience from a European center. Endoscopy 2017;49:222-232.

6. Nishizawa T, Yahagi N. Endoscopic mucosal resection and endoscopic submucosal dissection: technique and new directions. Curr Opin Gastroenterol 2017;33:315-319. 
7. Probst A, Golger D, Arnholdt H, Messmann H. Endoscopic submucosal dissection of early cancers, flat adenomas, and submucosal tumors in the gastrointestinal tract. Clin Gastroenterol Hepatol 2009;7:149-155.

8. Jacques J, Albouys J, Guyot A, et al. Endoscopic submucosal dissection of a laterally spreading tumor in the right colon with a gastroscope after shortening the colon using a new double-balloon platform. Endoscopy 2019;51:E364-E365.

9. Jawaid S, Yang D, Draganov PV. Tissue retractor system-assisted endoscopic submucosal dissection of a large rectal tumor with significant fibrosis from direct tattooing. VideoGIE 2019;4:84-86.

10. Mortagy M, Mehta N, Parsi MA, et al. Magnetic anchor guidance for endoscopic submucosal dissection and other endoscopic procedures. World J Gastroenterol 2017;23:2883-2890.

11. Walter B, Schmidbaur S, Krieger Y, Meining A. Improved endoscopic resection of large flat lesions and early cancers using an external additional working channel (AWC): a case series. Endosc Int Open 2019;7:E298-E301.

12. Oyama T. Counter traction makes endoscopic submucosal dissection easier. Clin Endosc 2012;45:375-378.

13. Imaeda $\mathrm{H}$, Hosoe $\mathrm{N}$, Kashiwagi $\mathrm{K}$, et al. Advanced endoscopic submucosal dissection with traction. World J Gastrointest Endosc 2014;6:286295

14. Tsuji K, Yoshida N, Nakanishi H, Takemura K, Yamada S, Doyama H. Recent traction methods for endoscopic submucosal dissection. World J Gastroenterol 2016;22:5917-5926.

15. Moher D, Shamseer L, Clarke M, et al. Preferred reporting items for systematic review and meta-analysis protocols (PRISMA-P) 2015 statement. Syst Rev 2015;4:1.

16. Higgins JPT, Green S. Cochrane handbook for systematic reviews of interventions version 5.1.0 [Internet]. London: Cochrane Training; c2011 [updated 2011 Mar; cited 2019 Feb 14]. Available from: https://training. cochrane.org/handbook/archive/v5.1/.

17. Stang A. Critical evaluation of the Newcastle-Ottawa scale for the assessment of the quality of nonrandomized studies in meta-analyses. Eur J Epidemiol 2010;25:603-605.

18. Yonezawa J, Kaise M, Sumiyama K, Goda K, Arakawa H, Tajiri H. A novel double-channel therapeutic endoscope ("R-scope") facilitates endoscopic submucosal dissection of superficial gastric neoplasms. Endoscopy 2006;38:1011-1015.

19. Gotoda T, Oda I, Tamakawa K, Ueda H, Kobayashi T, Kakizoe T. Prospective clinical trial of magnetic-anchor-guided endoscopic submucosal dissection for large early gastric cancer (with videos). Gastrointest Endosc 2009;69:10-15.

20. Imaeda $\mathrm{H}$, Hosoe $\mathrm{N}$, Ida $\mathrm{Y}$, et al. Novel technique of endoscopic submucosal dissection using an external grasping forceps for superficial gastric neoplasia. Dig Endosc 2009;21:122-127.

21. Motohashi O, Nishimura K, Nakayama N, Takagi S, Yanagida N. Endoscopic submucosal dissection (two-point fixed ESD) for early esophageal cancer. Dig Endosc 2009;21:176-179.

22. Uraoka T, Ishikawa S, Kato J, et al. Advantages of using thin endoscope-assisted endoscopic submucosal dissection technique for large colorectal tumors. Dig Endosc 2010;22:186-191.

23. Hijikata Y, Ogasawara N, Sasaki M, et al. Endoscopic submucosal dissection with sheath-assisted counter traction using a novel sheath for early gastric cancers. Hepatogastroenterology 2012;59:353-356.

24. Okamoto K, Muguruma N, Kitamura S, Kimura T, Takayama T. Endoscopic submucosal dissection for large colorectal tumors using a cross-counter technique and a novel large-diameter balloon overtube. Dig Endosc 2012;24 Suppl 1:96-99.

25. Okamoto K, Okamura S, Muguruma N, et al. Endoscopic submucosal dissection for early gastric cancer using a cross-counter technique. Surg Endosc 2012;26:3676-3681.

26. Ota M, Nakamura T, Hayashi K, et al. Usefulness of clip traction in the early phase of esophageal endoscopic submucosal dissection. Dig Endosc 2012;24:315-318.
27. Ahn JY, Choi KD, Lee JH, et al. Is transnasal endoscope-assisted endoscopic submucosal dissection for gastric neoplasm useful in training beginners? A prospective randomized trial. Surg Endosc 2013;27:11581165.

28. Higuchi K, Tanabe S, Azuma M, et al. Double-endoscope endoscopic submucosal dissection for the treatment of early gastric cancer accompanied by an ulcer scar (with video). Gastrointest Endosc 2013;78:266273.

29. Matsumoto K, Nagahara A, Ueyama H, et al. Development and clinical usability of a new traction device "medical ring" for endoscopic submucosal dissection of early gastric cancer. Surg Endosc 2013;27:3444-3451.

30. Ritsuno H, Sakamoto N, Osada T, et al. Prospective clinical trial of traction device-assisted endoscopic submucosal dissection of large superficial colorectal tumors using the S-O clip. Surg Endosc 2014;28:31433149.

31. Cai SL, Shi Q, Chen T, Zhong YS. Dental floss traction assists in treating gastrointestinal mucosal tumors by endoscopy. J Laparoendosc Adv Surg Tech A 2015;25:571-576.

32. Koike Y, Hirasawa D, Fujita N, et al. Usefulness of the thread-traction method in esophageal endoscopic submucosal dissection: randomized controlled trial. Dig Endosc 2015;27:303-309.

33. Noda H, Ogasawara N, Koshino A, et al. Thread-traction with a sheath of polypectomy snare facilitates endoscopic submucosal dissection of early gastric cancers. Gastroenterol Res Pract 2016;2016:9415497.

34. Suzuki S, Gotoda T, Kobayashi Y, et al. Usefulness of a traction method using dental floss and a hemoclip for gastric endoscopic submucosal dissection: a propensity score matching analysis (with videos). Gastrointest Endosc 2016;83:337-346.

35. Yamada S, Doyama H, Ota R, et al. Impact of the clip and snare method using the prelooping technique for colorectal endoscopic submucosal dissection. Endoscopy 2016;48:281-285.

36. Yamasaki Y, Takeuchi Y, Uedo N, et al. Traction-assisted colonic endoscopic submucosal dissection using clip and line: a feasibility study. Endosc Int Open 2016;4:E51-E55.

37. Yoshida M, Takizawa K, Ono H, et al. Efficacy of endoscopic submucosal dissection with dental floss clip traction for gastric epithelial neoplasia: a pilot study (with video). Surg Endosc 2016;30:3100-3106.

38. Jacques J, Legros R, Rivory J, et al. The "tunnel + clip" strategy standardised and facilitates oesophageal ESD procedures: a prospective, consecutive bi-centric study. Surg Endosc 2017;31:4838-4847.

39. Mori H, Kobara H, Nishiyama N, Fujihara S, Matsunaga T, Masaki T. Novel effective and repeatedly available ring-thread counter traction for safer colorectal endoscopic submucosal dissection. Surg Endosc 2017;31:3040-3047.

40. Ogata K, Yanai M, Kuriyama K, et al. Double endoscopic intraluminal operation (DEILO) for early gastric cancer: outcome of novel procedure for endoscopic submucosal dissection. Anticancer Res 2017;37:343-347.

41. Xie X, Bai JY, Fan CQ, et al. Application of clip traction in endoscopic submucosal dissection to the treatment of early esophageal carcinoma and precancerous lesions. Surg Endosc 2017;31:462-468.

42. Hashimoto R, Hirasawa D, Iwaki T, et al. Usefulness of the S-O clip for gastric endoscopic submucosal dissection (with video). Surg Endosc 2018;32:908-914.

43. Kitagawa Y, Suzuki T, Hara T, Yamaguchi T. Safety and efficacy of endoscopic submucosal dissection using IT knife nano with clip traction method for early esophageal squamous cell carcinoma. Surg Endosc 2018;32:450-455.

44. Matsuzaki I, Hattori M, Hirose K, et al. Magnetic anchor-guided endoscopic submucosal dissection for gastric lesions (with video). Gastrointest Endosc 2018;87:1576-1580.

45. Yamasaki Y, Takeuchi Y, Uedo N, et al. Efficacy of traction-assisted colorectal endoscopic submucosal dissection using a clip-and-thread technique: a prospective randomized study. Dig Endosc 2018;30:467-476.

46. Yoshida M, Takizawa K, Suzuki S, et al. Conventional versus traction-assisted endoscopic submucosal dissection for gastric neoplasms: 
a multicenter, randomized controlled trial (with video). Gastrointest Endosc 2018;87:1231-1240.

47. Zhang Q, Yao X, Cai JQ, Zhang BH, Wang Z. Snare combined with endoclips in endoscopic submucosal dissection with mucosal traction for gastroesophageal neoplasia. J Gastroenterol Hepatol 2019;34:1049-1057.

48. Çolak Ş, Gürbulak B, Çakar E, Bektaş H. Resection of mucosal and submucosal gastrointestinal lesions and a double endoscope experience.
JSLS 2019;23

49. Ye L, Yuan X, Pang M, et al. Magnetic bead-assisted endoscopic submucosal dissection: a gravity-based traction method for treating large superficial colorectal tumors. Surg Endosc 2019;33:2034-2041.

50. Zhang Q, Xing TY, Wang Z. A snare combined with endoclips to assist in endoscopic submucosal dissection for intraepithelial neoplasia in the entire colon and rectum. Scand J Gastroenterol 2019;54:114-121. 
Supplementary 1. Preferred Reporting Items for Systematic Reviews and Meta-Analyses Checklist

\begin{tabular}{|c|c|c|c|}
\hline Section/topic & $\#$ & Checklist item & $\begin{array}{l}\text { Reported on } \\
\text { page \# }\end{array}$ \\
\hline \multicolumn{4}{|l|}{ TITLE } \\
\hline Title & 1 & Identify the report as a systematic review, meta-analysis, or both. & 1 \\
\hline \multicolumn{4}{|l|}{ ABSTRACT } \\
\hline Structured summary & 2 & $\begin{array}{l}\text { Provide a structured summary including, as applicable: background; objectives; data } \\
\text { sources; study eligibility criteria, participants, and interventions; study appraisal and syn- } \\
\text { thesis methods; results; limitations; conclusions and implications of key findings; system- } \\
\text { atic review registration number. }\end{array}$ & 2 \\
\hline \multicolumn{4}{|l|}{ INTRODUCTION } \\
\hline Rationale & 3 & Describe the rationale for the review in the context of what is already known. & 4 \\
\hline Objectives & 4 & $\begin{array}{l}\text { Provide an explicit statement of questions being addressed with reference to participants, } \\
\text { interventions, comparisons, outcomes, and study design (PICOS). }\end{array}$ & 4 \\
\hline \multicolumn{4}{|l|}{ METHODS } \\
\hline $\begin{array}{l}\text { Protocol and registra- } \\
\text { tion }\end{array}$ & 5 & $\begin{array}{l}\text { Indicate if a review protocol exists, if and where it can be accessed (e.g., Web address), } \\
\text { and, if available, provide registration information including registration number. }\end{array}$ & 5 \\
\hline Eligibility criteria & 6 & $\begin{array}{l}\text { Specify study characteristics (e.g., PICOS, length of follow-up) and report characteristics } \\
\text { (e.g., years considered, language, publication status) used as criteria for eligibility, giving } \\
\text { rationale. }\end{array}$ & 5 \\
\hline Information sources & 7 & $\begin{array}{l}\text { Describe all information sources (e.g., databases with dates of coverage, contact with } \\
\text { study authors to identify additional studies) in the search and date last searched. }\end{array}$ & 5 \\
\hline Search & 8 & $\begin{array}{l}\text { Present full electronic search strategy for at least one database, including any limits used, } \\
\text { such that it could be repeated. }\end{array}$ & $\begin{array}{c}5-6 \\
\text { Supplementary } 2 \\
\end{array}$ \\
\hline Study selection & 9 & $\begin{array}{l}\text { State the process for selecting studies (i.e., screening, eligibility, included in systematic } \\
\text { review, and, if applicable, included in the meta-analysis). }\end{array}$ & 6 \\
\hline $\begin{array}{l}\text { Data collection pro- } \\
\text { cess }\end{array}$ & 10 & $\begin{array}{l}\text { Describe method of data extraction from reports (e.g., piloted forms, independently, in } \\
\text { duplicate) and any processes for obtaining and confirming data from investigators. }\end{array}$ & 6 \\
\hline Data items & 11 & $\begin{array}{l}\text { List and define all variables for which data were sought (e.g., PICOS, funding sources) } \\
\text { and any assumptions and simplifications made. }\end{array}$ & $6-7$ \\
\hline $\begin{array}{l}\text { Risk of bias in individ- } \\
\text { ual studies }\end{array}$ & 12 & $\begin{array}{l}\text { Describe methods used for assessing risk of bias of individual studies (including specifi- } \\
\text { cation of whether this was done at the study or outcome level), and how this information } \\
\text { is to be used in any data synthesis. }\end{array}$ & 9 \\
\hline Summary measures & 13 & State the principal summary measures (e.g., risk ratio, difference in means). & 7 \\
\hline Synthesis of results & 14 & $\begin{array}{l}\text { Describe the methods of handling data and combining results of studies, if done, includ- } \\
\left.\text { ing measures of consistency (e.g., } \mathrm{I}^{2}\right) \text { for each meta-analysis. }\end{array}$ & 8 \\
\hline
\end{tabular}




\begin{tabular}{|c|c|c|c|}
\hline Section/topic & $\#$ & Checklist item & $\begin{array}{l}\text { Reported on } \\
\text { page \# }\end{array}$ \\
\hline $\begin{array}{l}\text { Risk of bias across } \\
\text { studies }\end{array}$ & 15 & $\begin{array}{l}\text { Specify any assessment of risk of bias that may affect the cumulative evidence (e.g., publi- } \\
\text { cation bias, selective reporting within studies). }\end{array}$ & 9 \\
\hline Additional analyses & 16 & $\begin{array}{l}\text { Describe methods of additional analyses (e.g., sensitivity or subgroup analyses, meta-re- } \\
\text { gression), if done, indicating which were pre-specified. }\end{array}$ & 9 \\
\hline \multicolumn{4}{|l|}{ RESULTS } \\
\hline Study selection & 17 & $\begin{array}{l}\text { Give numbers of studies screened, assessed for eligibility, and included in the review, with } \\
\text { reasons for exclusions at each stage, ideally with a flow diagram. }\end{array}$ & 10 \\
\hline Study characteristics & 18 & $\begin{array}{l}\text { For each study, present characteristics for which data were extracted (e.g., study size, } \\
\text { PICOS, follow-up period) and provide the citations. }\end{array}$ & 10, Table 1 \\
\hline $\begin{array}{l}\text { Risk of bias within } \\
\text { studies }\end{array}$ & 19 & $\begin{array}{l}\text { Present data on risk of bias of each study and, if available, any outcome level assessment } \\
\text { (see item 12). }\end{array}$ & 11 \\
\hline $\begin{array}{l}\text { Results of individual } \\
\text { studies }\end{array}$ & 20 & $\begin{array}{l}\text { For all outcomes considered (benefits or harms), present, for each study: (a) simple } \\
\text { summary data for each intervention group (b) effect estimates and confidence intervals, } \\
\text { ideally with a forest plot. }\end{array}$ & $11-12$ \\
\hline Synthesis of results & 21 & $\begin{array}{l}\text { Present results of each meta-analysis done, including confidence intervals and measures } \\
\text { of consistency. }\end{array}$ & $12-17$ \\
\hline $\begin{array}{l}\text { Risk of bias across } \\
\text { studies }\end{array}$ & 22 & Present results of any assessment of risk of bias across studies (see Item 15). & $\begin{array}{l}\text { 12, Figure } 2 \text {, } \\
\text { Supplementary } 3\end{array}$ \\
\hline Additional analysis & 23 & $\begin{array}{l}\text { Give results of additional analyses, if done (e.g., sensitivity or subgroup analyses, meta-re- } \\
\text { gression [see Item 16]). }\end{array}$ & 14 \\
\hline \multicolumn{4}{|l|}{ DISCUSSION } \\
\hline Summary of evidence & 24 & $\begin{array}{l}\text { Summarize the main findings including the strength of evidence for each main outcome; } \\
\text { consider their relevance to key groups (e.g., healthcare providers, users, and policy mak- } \\
\text { ers). }\end{array}$ & $18-21$ \\
\hline Limitations & 25 & $\begin{array}{l}\text { Discuss limitations at study and outcome level (e.g., risk of bias), and at review-level (e.g., } \\
\text { incomplete retrieval of identified research, reporting bias). }\end{array}$ & 20 \\
\hline Conclusions & 26 & $\begin{array}{l}\text { Provide a general interpretation of the results in the context of other evidence, and impli- } \\
\text { cations for future research. }\end{array}$ & $20-21$ \\
\hline NDING $27 \quad$ I & & e sources of funding for the systematic review and other support (e.g., supply of data); role & \\
\hline
\end{tabular}


Supplementary 2. Search Strategy

\begin{tabular}{|c|c|c|c|}
\hline \multicolumn{4}{|c|}{ PubMed (Date Run: 18/05/19) } \\
\hline Step & Search strategy & Found & Time \\
\hline$\# 1$ & $\begin{array}{l}\text { Search "endoscopic mucosal resection"[MeSH Terms] OR ("endoscopic"[All Fields] AND “mucosal”[All } \\
\text { Fields] AND "resection"[All Fields]) OR "endoscopic mucosal resection"[All Fields] OR ("endoscop- } \\
\text { ic"[All Fields] AND "submucosal"[All Fields] AND "dissection”[All Fields]) OR "endoscopic submuco- } \\
\text { sal dissection"[All Fields] }\end{array}$ & 7,036 & 11:30:06 \\
\hline$\# 2$ & Search “traction”[MeSH Terms] OR “traction”[All Fields] & 22,511 & $11: 33: 29$ \\
\hline$\# 3$ & \#1 OR \#2 AND English[lang] & 146 & $11: 34: 50$ \\
\hline
\end{tabular}

\begin{tabular}{llc}
\hline \multicolumn{2}{c}{ Cochrane Central Register of Clinical Trials (Date Run: 18/05/19) } & \\
\hline ID & Search strategy & Found \\
\hline$\# 1$ & ("endoscopic submucosal dissection") (Word variations have been searched):ti,ab,kw & 687 \\
\hline$\# 2$ & ("traction”) (Word variations have been searched) & 1,838 \\
\hline$\# 3$ & $\# 1$ AND \#2 & 31 \\
\hline
\end{tabular}




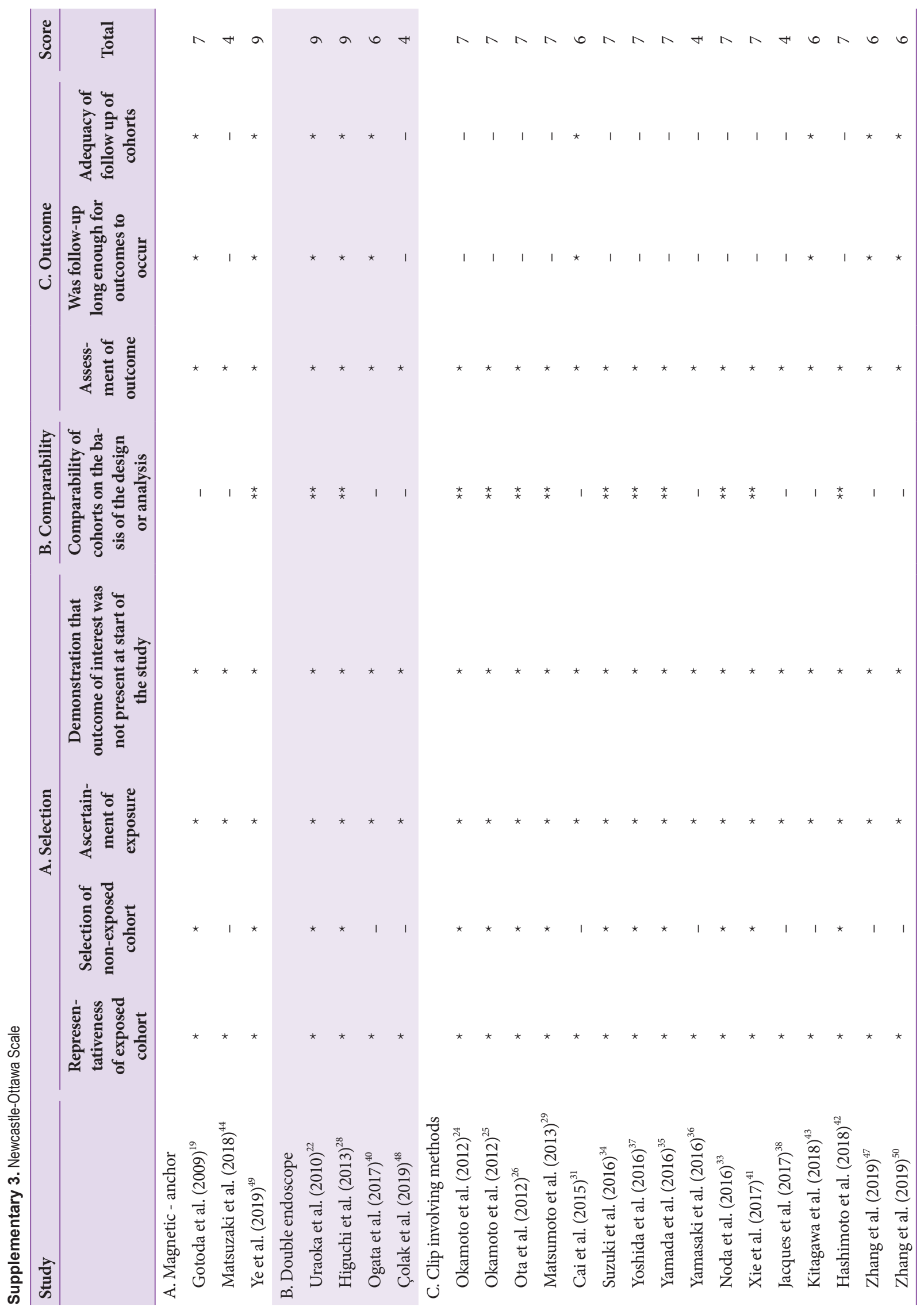


C clinical endoscopy

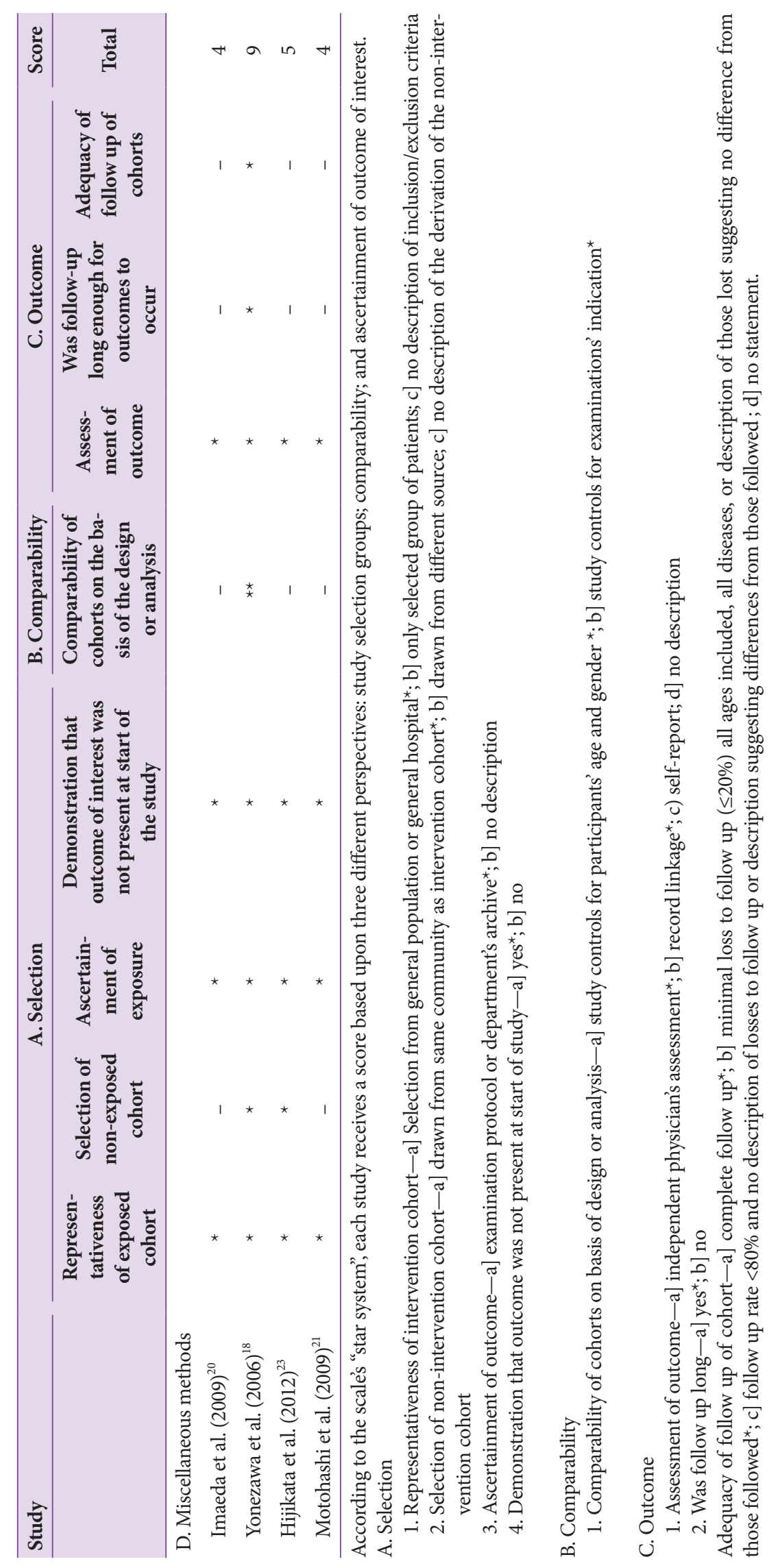

